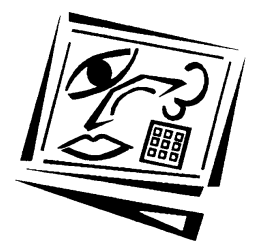

\title{
Wiki activities in blended learning for health professional students: Enhancing critical thinking and clinical reasoning skills
}

\author{
Suzanne Snodgrass \\ The University of Newcastle
}

\begin{abstract}
Health professionals use critical thinking, a key problem solving skill, for clinical reasoning which is defined as the use of knowledge and reflective inquiry to diagnose a clinical problem. Teaching these skills in traditional settings with growing class sizes is challenging, and students increasingly expect learning that is flexible and interactive. This paper describes the implementation and evaluation of a blended method for teaching clinical reasoning using a wiki. Groups of undergraduate physiotherapy students presented a patient case to their peers in class and on a wiki. Evaluation included student surveys, focus groups, and online participation. Students were actively involved in the wiki (mean contribution of 21.0 web pages (IQR 7.5-34.5). Most students (74\%) agreed the inclass sessions were valuable, compared to $48 \%$ for the wiki. From the educator's perspective, the wiki facilitated collaboration, ensuring demonstrated reasoning skills in class. Combining wiki with in-class activities enhances student collaboration and learning of critical thinking skills.
\end{abstract}

\section{Introduction}

Blended learning methods incorporating e-learning are increasingly being utilised in higher education. This is observed at its simplest level by the provision of electronic resources for on campus students, though the complexity increases when interactive online activities are coupled with face to face teaching. One method of online interaction is the wiki. A wiki is a type of web site that allows users to create and edit content using their web browsers (Leuf \& Cunningham, 2001). Interest in facilitating learning using interactive online content is growing. This is evident in the many publications, websites and now conferences (Riehle \& Bruckman, 2009) that revolve around this topic.

In the health professions, students must use critical thinking skills to master clinical reasoning. Clinical reasoning requires knowledge, cognition, reflective inquiry and metacognition (Higgs \& Jones, 2008; Turpin \& Higgs, 2010), and represents the key problem solving skill for health practitioners. Teaching the skills needed for clinical reasoning is challenging, especially in the traditional classroom environment. It requires simulating the work environment, where decision making is based on a complex series of interactions with patients and other involved professionals. In addition, today's generation of students are demanding immediate interactive learning that is flexible (Pasole \& Awalt, 2008). Addressing the need to stimulate the work environment and provide flexible learning, a blended learning method integrating a 
wiki was developed for teaching clinical reasoning. This paper describes the introduction and evaluation of this blended learning method in the teaching of clinical reasoning in a health science course.

\section{Using wikis in teaching}

\section{Collaborative learning}

Collaborative learning has been associated with higher achievement, greater motivation and engagement amongst students, and positive attitudes towards study (Neumann \& Hood, 2009). Collaboration during learning contrasts with the traditional learning environment where the focus is competition for the highest grade. Wikis facilitate collaborative learning, engaging students with educators in an asynchronous manner (Elgort, Smith \& Toland, 2008). They also provide a record of student collaboration and function as a knowledge repository for future review by students (Brack \& Van Damme, 2009). Using the collaborative environment of a wiki, students' learning focus changes to one of sharing knowledge rather than competing for achievement.

As well as creating and sharing information, a key advantage of using a wiki for collaborative learning is its organisational capacity (Staley, 2009). Wikis can assist collaboration in an environment where large class sizes and limited face to face time present barriers to student interaction (Brack \& Van Damme, 2009). They provide flexibility for students with conflicting class times, work and social commitments (Carr, 2008). Collaboration using a wiki facilitates organisation of multiple perspectives leading to construction of a deeper understanding of the topic of interest (Ruth \& Houghton, 2009).

There are some limitations to using a wiki to facilitate collaborative learning. Students often dislike group work and may feel daunted by online learning and collaboration, often reporting confusion and uncertainty about what is required of them (Wheeler, Yeomans \& Wheeler, 2008). Wikis allow students to work collaboratively to overcome these difficulties. However, students may tend to only read the information to which they contributed, and may be protective or wish to take individual credit for their own work or ideas in a group (Wheeler, et al., 2008), which presents obstacles for student collaboration. Fortunately, wikis encourage collaboration while also having the ability to record and evaluate individual participation, increasing their validity as an assessment tool (Trentin, 2009).

Using a wiki in collaborative group work harnesses social processes to help students communicate and work together to create new knowledge and understanding. Developing an online identity facilitates learning through building social networks, communication with teachers and peers, and increased motivation for participation (Stahmer, 2006). Interaction and engagement of individuals is encouraged through casual discussion and the freedom of expression offered by a web-based social environment (Wheeler, et al., 2008). Students may benefit from viewing how other students on the wiki approach problems, and research indicates that some students learn even when they do not directly contribute to discussion (Beaudoin, 2002). Collaborative learning is reflective of the multidisciplinary approach used by professionals in the workplace. The use of a wiki can enhance collaboration through innovative methods that are appropriate for preparing today's students for the workplace using emerging technologies. 
Types of wikis for teaching and learning

Wikis can be used to facilitate learning through group collaboration for the presentation of knowledge, either written or oral. Classroom-based wikis are those created by teachers and students, and are not usually accessible to the public (McPherson, 2006). The wiki acts as a gateway for discussion, simulating a learning environment, or can be used to delegate tasks and encourage planning within groups (Caverly \& Ward, 2008). Wikis allow collaborative editing of pages by participants and many other functions depending on the purpose and software used. Emerging in the mid-1990s, wikis are now increasing in popularity, particularly for teaching and learning. They are appropriate for use in education due to their user friendliness, flexibility and low cost (Zorko, 2009). Wikis are used in a wide variety of learning settings (Bold, 2006; Choy \& Ng, 2007), from art and multimedia (Buffington, 2008; Chen, 2007) to education (Carr, 2008) and health (Ciesielka, 2008). Most usage revolves around collaborative learning with a specific aim. For example, art students used a wiki to increase their interpretation and understanding of specific works of art (Buffington, 2008), multimedia design students used a wiki to display and share projects online (Chen, 2007), and graduate nursing students used a wiki to complete a project in community health (Ciesielka, 2008). Wikis can be used by teachers to aid learning through sharing and storage of digital information, and monitoring progress of student groups or individuals (Augar, Raitman \& Zhou, 2006; Choy \& Ng, 2007; Nicol, Littlejohn \& Grierson, 2005) They have significant potential for accelerating collaboration among educators, researchers and students, however empirical research is limited.

\section{Advantages}

Using a wiki strengthens collaborative learning, provides a record of information and accommodates different learning styles and speeds of learning. Wikis are more feasible for group work when face to face interactions are limited (Sheehy, 2008). They enhance social benefits through supportive interaction with peers (McIntosh \& Weaver, 2008), and they are particularly suitable for today's generation of students who have used the Internet for most of their lives (Oblinger, 2005). Students have quick and easy access to information (Matthew \& Felvegi, 2009), and can edit pages from independent locations without the hassle of computer software incompatibilities (Ben-Zvi, 2007). It is believed that the time delay in communication gives the reader a chance to reflect before posting a reply (Arnold \& Ducate, 2006), promoting critical thinking skills. There is also a strong desire among students to write accurate and relevant content, due to the knowledge that peers and teachers will be viewing their work (Wheeler \& Wheeler, 2009).

\section{Difficulties}

Students report both positive and negative experiences when using wikis. It is a new experience for most learners and therefore it is important to not overestimate the technical skills of students. Two studies report technological barriers for students when using wikis (Matthew \& Felvegi, 2009; Oblinger, 2005). Some students have expressed dissatisfaction with wikis and felt overwhelmed by the technical aspects (Zorko, 2009), particularly tasks such as inserting figures and tables (Neumann \& Hood, 2009). This could be addressed by providing additional instruction and training in how to use a wiki.

Wikis promote creativity and freedom of expression, but this may introduce learning challenges for some students. Organisational problems may arise from students posting superfluous materials (Ruth \& Houghton, 2009), lack of student contribution 
(Wheeler, et al., 2008) and large amounts of information on wiki pages without any apparent structure or flow (Matthew \& Felvegi, 2009). Although the wiki technology may become more familiar to students the more they use it, not all students are comfortable learning in the online environment (Matthew \& Felvegi, 2009). In one study, some students believed their wiki restricted their writing style, and were reluctant to edit content posted by their peers (Wheeler \& Wheeler, 2009). This highlights the value of blended learning methods that can better accommodate different learning styles and abilities, when incorporating a wiki.

\section{Blended learning methods}

Blended learning is the effective combination of different methods of delivery, models of teaching and styles of learning (Proctor, 2003). It defines learning activities, location (online or in class), ownership (individual or group) and the technologies and methods used to support learning (Cubric, 2007). There is evidence that a wiki can be integrated with face to face teaching to support student learning in university courses (Heinze \& Procter, 2004; Michalski, 2008; Neumann \& Hood, 2009). Wikis may be beneficial in a blended learning approach that complements contemporary teaching of clinical reasoning in health professional courses.

\section{Clinical reasoning}

Clinical reasoning is a thinking and decision making process requiring knowledge, cognition, metacognition and reflective enquiry (Higgs \& Jones, 2008). Effective clinical reasoning is essential for all health professionals to justify and account for their clinical decisions (Ajjawi \& Higgs, 2008). It is patient-centred, collaborative, hypothesis oriented and incorporates best judgment into decision making (Jones \& Rivett, 2004). Complex clinical situations require health professionals to integrate information from the client, evidence based research, and their own health knowledge and experiences to provide appropriate diagnoses, assessment and treatment (Turpin \& Higgs, 2010).

Teaching of clinical reasoning requires matching the process of learning programs to the content, goals and learning outcomes of health professional courses (Higgs, 2004). Historically, there has been more focus on teaching basic science and knowledge rather than clinical reasoning (Kaufman, Yoskowitz \& Patel, 2008). Curricula have begun to change in recent years, as health professional graduates are expected to be competent and autonomous, with strong problem solving and technological skills (Hunt \& Higgs, 1999). This is coupled with an increasing proliferation of new knowledge, which requires practitioners to continually re-evaluate their clinical practice as they appraise and incorporate new evidence into their clinical decision making. With the increasing importance of evidence based practice, there is growing need for clinical reasoning skills to collect and interpret new and varied information sources (Turpin \& Higgs, 2010).

Online technology is emerging as a tool to facilitate the learning of clinical reasoning (Tan, Ladyshewsky \& Gardner, 2010). The wiki is one online medium that can provide a collaborative environment in which students can use critical thinking skills to discuss, negotiate, share and reflect on thoughts and learning processes (Ruth \& Houghton, 2009). The review and editing processes used in wiki applications are reported to encourage metacognition and reflective skills in students (Kirschner, 2004). The learning of critical thinking skills through wiki use is also supported by one report stating that students viewed wiki-based information as not necessarily trustworthy without supporting evidence, and there was increased awareness of the importance of 
developing critical, analytical and reflective skills through using wikis (Wheeler \& Wheeler, 2009). Wiki learning offers a new method of clinical reasoning teaching that may encourage participation and engagement, integrate knowledge with simulated clinical situations, and accommodate different learning styles.

\section{Background to the teaching project}

Students completing their third year of undergraduate physiotherapy training participate in a Clinical Reasoning Learning Program that develops their skills in clinical decision making and consolidates knowledge from their first three years of study. Students present and discuss simulated patient cases representing a variety of clinical environments. They integrate physiotherapy knowledge with multidisciplinary concepts and patient-centred treatment. The Clinical Reasoning Learning Program provides a link between classroom and workplace learning, enabling skill-building prior to professional placements. It addresses all levels of learning, not just factual recall but also critical thinking and application (Anderson \& Krathwohl, 2001).

Growing student numbers necessitated a new approach to the teaching of clinical reasoning. There is evidence that class sizes are growing in higher education and resources shrinking (Bradley, Noonan, Nugent \& Scales, 2008). At the time the project was conducted, there was also a critical shortage of allied health professionals which highlighted the need to educate more students (Health Professions Council of Australia, 2005). Thus, there was an urgent need to find new and efficient ways of stimulating students' critical thinking in large groups.

To enable all students to participate and engage in learning clinical reasoning, it was important for students to be able to construct, discuss and share their decision making processes for a patient case with guidance from a knowledgeable teacher. Another intention of the Clinical Reasoning Learning Program was to expose the entire student cohort to a comprehensive variety of patient cases and generate discussion. This meant finding adequate face to face time within the student timetable to present a variety of patient cases, and having adequate student mentoring for case preparation.

A key impetus for implementing the new teaching approach was the changing demographics and perceived needs of today's generation of students. Today's students communicate online using social networking that is increasingly interactive (e.g. Facebook) and immediate (e.g. Twitter). Current reports indeed agree that 'Generation $\mathrm{Y}^{\prime}$ can be labelled as the 'now' generation (Burgess, 2008). This project attempted to harness some of the energy students expend on their online social networking and apply it to learning clinical reasoning. The aims of using the blended learning method were to facilitate student collaboration and interaction with clinical mentors, link learning to the workplace setting, and generate discussion of critical decision making skills and the reasoning accompanying those decisions. The purpose of this paper is to describe the implementation and evaluation of this blended learning method and offer suggestions for learning and teaching based on this experience.

\section{Methodology}

\section{Description of the blended learning method}

An interactive wiki was introduced in the teaching of clinical reasoning for third year undergraduate physiotherapy students. Students worked together to prepare a patient 
case in assigned groups of six or seven. Each student group presented their patient case in class and on a classroom wiki. Student performance in a previous course ensured allocation of proportionate levels of skills within each group. This was done to ensure adequate preparation in each group so that the material presented would be potentially useful for learning by the remainder of the class. Each group met with the course coordinator for 30 minutes at the start of the term to discuss their assigned patient case, and two groups per week presented their case in a weekly session scheduled throughout the semester. Students also contacted the course coordinator for advice as needed. Each week throughout the teaching term, two student groups presented their patient case to the rest of the student body in a single, two-hour, face to face clinical reasoning session (one hour per group).

Prior to the start of the teaching term, the course coordinator created the wiki using free online software (http://www.wetpaint.com/). This software allows anyone with a word processor to create websites. The wiki was private so that only individuals invited by the course coordinator had access, and it was free of advertisements. In addition to the students, clinical mentors were invited to join the wiki site. Clinical mentors were practising clinicians who worked in a clinical area relevant to each patient case. Each clinical mentor first confirmed they could participate, and then they were assigned to a student group. The course coordinator gave clinical mentors basic information about their group's patient case and its learning aims prior to their involvement in the wiki. Clinical mentors were encouraged to communicate with students using the wiki, but to avoid completing work for students by making major edits or large contributions to their web pages.

A single wiki was used for the whole class rather than individual group wikis, so that all students had the opportunity to learn from and discuss other group's cases. On the wiki, webpage headings labelled each patient case. Students then created new web pages as subheadings beneath the name of their case. Discussion threads at the bottom of each webpage allowed mentors and students to discuss topics relevant to the webpage. Students could also add attachments to web pages or to discussion threads. Students were encouraged to include text, images, videos, links and any other resources relevant to their case. All students had access to all web pages on the wiki site, and they could edit or add to all pages. However, only the course coordinator could delete web pages from the site.

In addition to the wiki, students also completed a Learning Journal that would assist in tracking their own learning of each patient case. The Learning Journal consisted of 'mind maps', reflections, and an independent patient interview activity, and was marked as a contribution to the overall clinical reasoning mark. Students completed a mind map about each week's topic and submitted this at the start of the face to face session. After each session, students reflected on what they learned about the types of patients presented and on any aspects that required further revision. Reflections were to include thoughts about any learning from either the in-class session or subsequent discussion on the wiki about the case, and they were submitted at the start of the following week's session. These one-page activities helped focus students' learning during weeks when they were not presenting the patient case. The patient interview activity consisted of students individually interviewing a mock patient while they were peer reviewed by another student. Mock patients were required to be individuals outside the physiotherapy discipline, which required students to avoid jargon in their interview. The interview activity was included to provide an authentic form of 
feedback to individuals about their clinical reasoning, as the primary learning activities were online or lecture, and group based. The patient interview activity was not linked to the wiki, but rather, provided an opportunity for students to individually put into practice the interview skills they learned by working to prepare their patient case or observing other group's cases.

The course coordinator presented a one hour introduction to clinical reasoning at the start of the semester. This included instructions explaining about wikis and how to use them, instructions about presenting patient cases, and how to use the Learning Journal. This provided clear instructions for students as to what was expected of them in this somewhat complex set of learning activities. In addition to the one-hour introduction, the course coordinator presented the first patient case as an example of what was expected of students. The first patient case was presented on the wiki site as well.

The clinical reasoning learning activities represented $10 \%$ of students' final mark for the course. The clinical reasoning mark (100\%) was divided into four equal parts weighted 25\% each: group mark for the in class presentation, group mark for the wiki content, individual marks for contributions in class and on the wiki, and individual marks for the Learning Journal. Marks were assigned using criterion-referenced marking. Wiki contributions were calculated based on data obtained from the wiki: numbers of web pages edited and words added.

\section{Data collection}

To gauge student response to the blended learning method, three types of data were collected. First, a paper-based survey was administered in class to all students in the course in attendance at a lecture in the final week of the teaching term after the completion of all clinical reasoning sessions. The survey included open ended, Likertstyle and 'fill in the blank' questions. Second, three focus groups were held in the final two weeks of the teaching term. All 58 students were invited to participate, and a total of 10 students attended in focus groups of 5, 3 and 2. These covered seven topics: learning clinical reasoning, the wiki, the clinical mentors, attendance at sessions, the Learning Journal, assessment and student effort. All students were invited to participate in focus groups and food was provided. A research assistant led the focus groups, which were recorded and transcribed. A careful sign-up process ensured that the course coordinator did not know which students participated in the focus groups, allowing students to give unencumbered responses.

Lastly, Google Analytics determined usage patterns on the wiki, including number of views per page and time spent on each page, stratified by week of term and by patient case. Individual student participation was calculated from wiki participation data collected for student marking. Though contributions to the wiki were counted, a threshold for quality of contribution was used, and only those of adequate quality were included in the count. The project was approved as a quality assurance activity by the University's Human Research Ethics Office, and data was collected from June to November 2009.

\section{Data analysis}

The Likert and 'fill in the blank' questions on the survey were analysed using descriptive statistics. All continuous variables were checked for normality, and nonparametric statistics (median and inter-quartile range, IQR) are reported where 
appropriate. For Likert questions, the percentage of students selecting each response was calculated. For student effort, the number of hours is reported as a mean with $95 \%$ confidence interval. These data were analysed in PASW 17.0 (SPSS Inc., an IBM Company, Chicago, USA).

The responses to the open-ended questions from the survey were combined with the focus group data and analysed thematically in Nvivo 8.0 (QSR International, Melbourne, Australia). Two reviewers independently identified the most common themes communicated by students in either the focus groups or survey questions. Common themes were agreed upon by the two reviewers through discussion. Then, each reviewer independently identified the number of student responses within each theme. Where there were differences in the number of student responses identified for a particular theme, the higher number of responses is reported.

\section{Results}

\section{Learning}

Table 1 contains the outcomes of the Likert questions on the survey. The results indicate that the majority of students agreed or strongly agreed that the in class sessions were valuable for their learning $(74.1 \%)$, and about half agreed the wiki was valuable $(48.2 \%)$. Most students agreed the Learning Journal $(55.2 \%)$ and the history taking practice $(68.9 \%$ ) were useful, and many felt they would use the wiki to further review before attending a placement in the clinical setting $(64.3 \%)$.

Table 2 is a summary of students' estimation of the number of hours they spent completing clinical reasoning tasks. Students spent more time working on their own patient case (mean 15.0 hours, SD 9.7) than learning from others' cases (1.1 hours, SD 0.9 ). Table 3 contains a list of the most common comments made about the clinical reasoning activities in the open-ended survey questions or in the focus groups. A wide variety of responses were collected, with the most commonly mentioned themes being their consolidation of knowledge through the program (37 total responses), and their belief that assessment was under-weighted for the importance they placed on the learning activities (65 total responses).

\section{Wiki participation}

Each student contributed to a median of 21.0 web pages (IQR 7.5 to 34.5 ). They added a median of 30.2 words per page (IQR 4.6 to 55.8). Though the average wiki contribution was reasonably high, individual student data indicated some students made minimal contributions to the wiki (0-1 webpage contributions for 6 students), and a small number of high achieving students made large contributions which were much greater than the norm (more than 100 webpage contributions and more than 3000 total words added for the highest 5 contributors in each of these categories). The majority of contributions for each student related to their own case, however, high performing students contributed significantly to discussion of other group's cases, enhancing the learning interaction. Figure 1 shows the number of unique page views by teaching week. The weeks with very low numbers of page views were weeks that students were off campus (in weeks 8-11, students were on full time clinical placements, and the mid semester break occurred during weeks 12-13). 
Table 1: Student responses $(\mathrm{n}=58)$ to paper-based survey questions (Likert scale)

\begin{tabular}{|c|c|c|c|c|c|}
\hline Item & \begin{tabular}{|c|} 
Strongly \\
agree \\
$\mathrm{N}(\%)$ \\
\end{tabular} & $\begin{array}{l}\text { Agree } \\
\mathrm{N}(\%)\end{array}$ & $\begin{array}{l}\text { Neutral } \\
\mathrm{N}(\%)\end{array}$ & $\begin{array}{l}\text { Disagree } \\
\mathrm{N}(\%)\end{array}$ & $\begin{array}{c}\text { Strongly } \\
\text { disagree } \\
\mathrm{N}(\%)\end{array}$ \\
\hline $\begin{array}{l}\text { I feel that the clinical reasoning sessions } \\
\text { helped me consolidate and revise my } \\
\text { musculoskeletal content. }\end{array}$ & $\begin{array}{c}7 \\
(12.1)\end{array}$ & $\begin{array}{c}40 \\
(69.0)\end{array}$ & $\begin{array}{c}8 \\
(13.8)\end{array}$ & $\begin{array}{c}3 \\
(5.2)\end{array}$ & $\begin{array}{c}0 \\
(0.0)\end{array}$ \\
\hline $\begin{array}{l}\text { I feel that the clinical reasoning sessions } \\
\text { are valuable in my preparation for my } \\
\text { musculoskeletal clinical placement. }\end{array}$ & $\begin{array}{c}8 \\
(13.8)\end{array}$ & $\begin{array}{c}35 \\
(60.3)\end{array}$ & $\begin{array}{c}13 \\
(22.4)\end{array}$ & $\begin{array}{c}2 \\
(3.4)\end{array}$ & $\begin{array}{c}0 \\
(0.0)\end{array}$ \\
\hline $\begin{array}{l}\text { I feel that the clinical reasoning wiki } \\
\text { helped me consolidate and revise my } \\
\text { musculoskeletal content. }\end{array}$ & $\begin{array}{c}4 \\
(6.9)\end{array}$ & $\begin{array}{c}19 \\
(32.8)\end{array}$ & $\begin{array}{c}15 \\
(25.9)\end{array}$ & $\begin{array}{c}13 \\
(22.4)\end{array}$ & $\begin{array}{c}7 \\
(12.1)\end{array}$ \\
\hline $\begin{array}{l}\text { I feel that the clinical reasoning wiki is } \\
\text { valuable in my preparation for my } \\
\text { musculoskeletal clinical placement. }\end{array}$ & $\begin{array}{c}6 \\
(10.3)\end{array}$ & $\begin{array}{c}22 \\
(37.9)\end{array}$ & $\begin{array}{c}16 \\
(27.6)\end{array}$ & $\begin{array}{c}10 \\
(17.2)\end{array}$ & $\begin{array}{c}4 \\
(6.9)\end{array}$ \\
\hline $\begin{array}{l}\text { The feedback I received from clinical } \\
\text { mentors on the wiki helped me learn. }\end{array}$ & $\begin{array}{c}4 \\
(6.9)\end{array}$ & $\begin{array}{c}23 \\
(39.7)\end{array}$ & $\begin{array}{c}15 \\
(25.9)\end{array}$ & $\begin{array}{c}9 \\
(15.5)\end{array}$ & $\begin{array}{c}7 \\
(12.1)\end{array}$ \\
\hline $\begin{array}{l}\text { Completing my learning journal by refl- } \\
\text { ecting on my clinical reasoning know- } \\
\text { ledge was useful in helping me learn. }\end{array}$ & $\begin{array}{c}3 \\
(5.2)\end{array}$ & $\begin{array}{c}29 \\
(50.0)\end{array}$ & $\begin{array}{c}14 \\
(24.1)\end{array}$ & $\begin{array}{c}10 \\
(17.2)\end{array}$ & $\begin{array}{c}2 \\
(3.4)\end{array}$ \\
\hline $\begin{array}{l}\text { The history taking practice was a useful } \\
\text { activity that helped improve my skills. }\end{array}$ & $\begin{array}{c}2 \\
(3.4)\end{array}$ & $\begin{array}{c}38 \\
(65.5)\end{array}$ & $\begin{array}{c}8 \\
(13.8)\end{array}$ & $\begin{array}{c}7 \\
(12.1)\end{array}$ & $\begin{array}{c}3 \\
(5.2)\end{array}$ \\
\hline $\begin{array}{l}\text { Overall, I am satisfied with the quality of } \\
\text { this clinical reasoning activity }\end{array}$ & $\begin{array}{c}4 \\
(6.9)\end{array}$ & $\begin{array}{c}29 \\
(50.0)\end{array}$ & $\begin{array}{c}14 \\
(24.1)\end{array}$ & $\begin{array}{c}10 \\
(17.2)\end{array}$ & $\begin{array}{c}0 \\
(0.0)\end{array}$ \\
\hline $\begin{array}{l}\text { I think the clinical reasoning activities } \\
\text { (sessions and wiki) should continue in } \\
\text { their current form for future students }\end{array}$ & $\begin{array}{c}6 \\
(10.3)\end{array}$ & $\begin{array}{c}22 \\
(37.9)\end{array}$ & $\begin{array}{c}12 \\
(20.7)\end{array}$ & $\begin{array}{c}12 \\
(20.7)\end{array}$ & $\begin{array}{c}3 \\
(5.2)\end{array}$ \\
\hline $\begin{array}{l}\text { I will use the wiki to review before my } \\
\text { musculoskeletal clinical placements }\end{array}$ & $\begin{array}{c}12 \\
(20.7)\end{array}$ & $\begin{array}{c}24 \\
(41.4)\end{array}$ & $\begin{array}{c}12 \\
(20.7)\end{array}$ & $\begin{array}{c}7 \\
(12.1)\end{array}$ & $\begin{array}{c}1 \\
(1.7)\end{array}$ \\
\hline
\end{tabular}

${ }^{*}$ Missing responses for these items so numbers do not sum to 58.

Table 2: Student reporting of their estimated number of hours working on the clinical reasoning activities

\begin{tabular}{|l|c|c|c|}
\hline & Mean & SD & $95 \%$ CI \\
\hline $\begin{array}{l}\text { Hours per week for all activities (not including weekly attendance at } \\
\text { in class sessions) }\end{array}$ & 2.74 & 3.80 & $1.73,3.75$ \\
\hline $\begin{array}{l}\text { Total hours for preparation of patient case, including wiki and in class } \\
\text { presentation }\end{array}$ & 15.00 & 9.74 & 12.39, \\
\hline Hours per week reviewing patient cases from other groups on the wiki & 1.05 & 0.93 & $0.8,1.3$ \\
\hline
\end{tabular}

\section{Discussion}

Most students reported the in class clinical reasoning sessions were beneficial for their learning, helping them consolidate and revise content, and prepare for clinical placements. Fewer students reported the wiki as valuable, though some indicated it was a good resource for revision and a valuable tool for collaboration. Others felt it was time intensive and cumbersome, and were concerned about the accuracy of the information on the wiki. Most students agreed the clinical mentors, learning journal and history taking activities helped them learn, though these numbers were slightly lower than for the in class sessions. Students spent considerable time outside of class on the clinical reasoning activities, with a large number of hours spent on preparation of their patient case. They felt their clinical reasoning assessment mark should have 
Table 3: Themes from open-ended responses in survey and focus groups ( $\mathrm{n}=$ number of times a theme was mentioned by a student)

\begin{tabular}{|l|c|c|}
\hline & Survey (n) & Focus groups (n) \\
\hline Clinical reasoning program consolidated knowledge & 23 & 14 \\
\hline Clinical reasoning program simulated the real experience & 13 & 3 \\
\hline Clinical Reasoning sessions were necessary and useful & 13 & 17 \\
\hline Wanted more focus on clinical decision making/treatment & 6 & 16 \\
\hline Wiki was useful & 2 & 6 \\
\hline Wiki was a valuable tool for collaboration & 8 & 7 \\
\hline Wiki was time intensive and cumbersome & 9 & 30 \\
\hline Wiki is good for revision, and to use as a resource & 3 & 7 \\
\hline Concerned about accuracy of information on wiki & 3 & 7 \\
\hline Mentors were highly useful, wanted more input from mentors & 12 & 29 \\
\hline Reflections were useful & 10 & 9 \\
\hline Mind maps were not useful & 6 & 5 \\
\hline $\begin{array}{l}\text { Assessment was underweighted for the importance of the } \\
\text { activity and the time involved }\end{array}$ & 33 & 32 \\
\hline $\begin{array}{l}\text { Wanted a system to help self-regulate and report group work } \\
\text { distribution }\end{array}$ & 6 & 8 \\
\hline Wanted a weekly quiz to help stay on track with learning & 3 & 7 \\
\hline
\end{tabular}

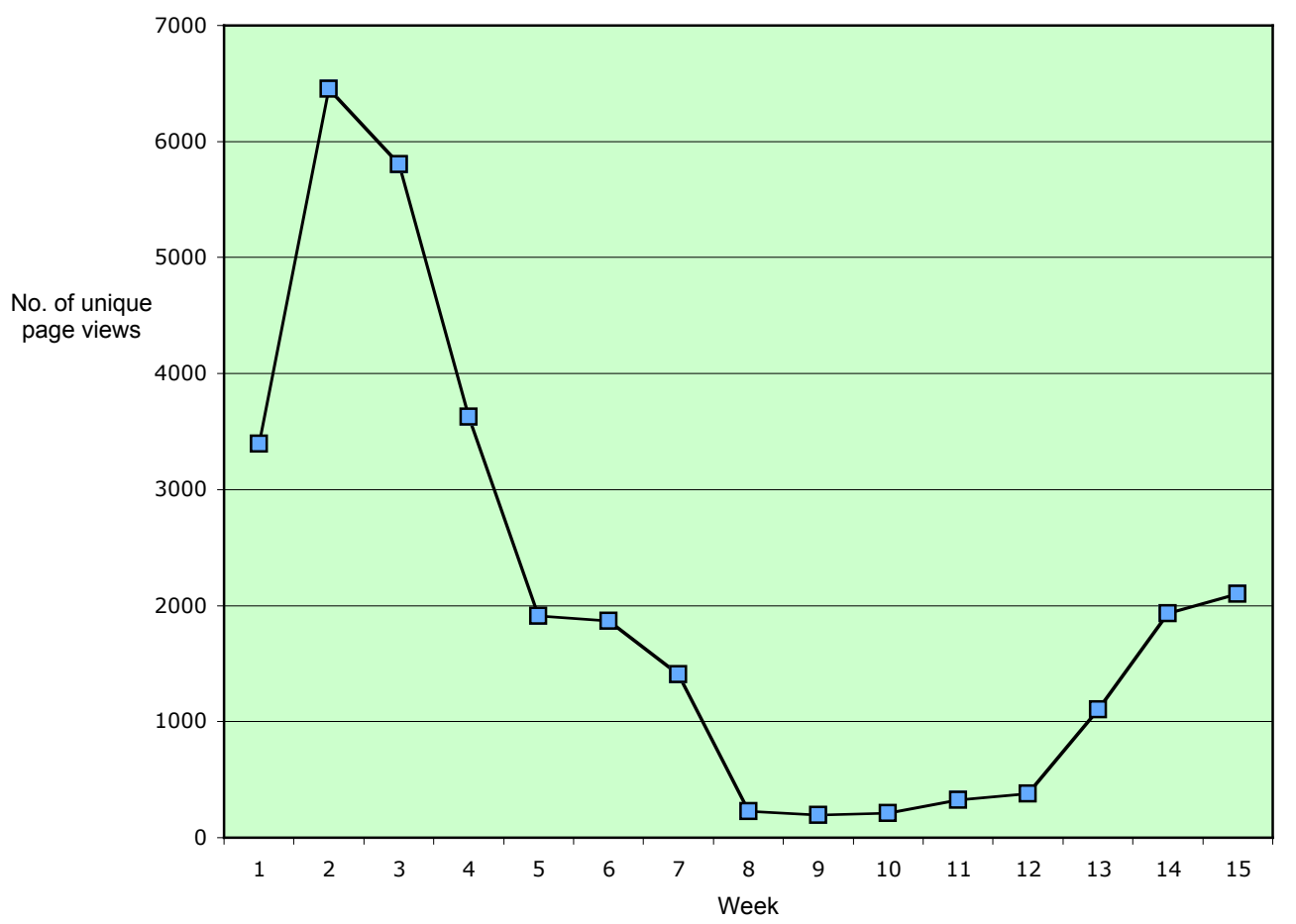

Figure 1: Number of unique page views on the wiki by week

represented a higher percentage of their overall course mark due to the importance they placed on the activity and the time involved. Overall, a majority of students were satisfied with the quality of the clinical reasoning activity, and reported they will use the wiki to review before clinical placements. These findings demonstrate that health 
students engage with a blended learning method incorporating a wiki, and they are able to view it as a useful tool for preparing them for the workplace setting.

\section{Collaborative learning using blended learning methods}

It has been suggested that wikis are the most appropriate online medium for collaborative learning (Elliot, 2007). The findings of the current study support the use of a wiki for facilitating collaboration to enhance student learning, consistent with previous research (Brack \& Van Damme, 2009; Elgort, et al., 2008; Ruth \& Houghton, 2009; Staley, 2009). These previous studies explored the learning effects of using a wiki alone and there were few identified studies investigating the integration of a wiki in blended learning models. One study by Neumann \& Hood (2009) that used a wiki as part of a blended learning approach for first year university statistics students reported it helped learning, technology was easily used, and it facilitated interaction among individuals in the group. Similarly, Cubric (2007) found business students demonstrated more active engagement and appreciation for collaborative learning when using a wiki. Giannoukos et al. (2008) propose the blended learning method integrating a wiki results in better group coordination and participation, enhancing student interaction and collaboration. Other previous studies suggest that students often work cooperatively but as individuals within a wiki, rather than working collaboratively. In the current study, delegation of initial tasks within a group was observed, but the desire of students to produce quality content in their wiki facilitated group collaboration through ongoing editing of content by a group (Judd, Kennedy \& Cropper, 2010; Weaver, Viper, Latter \& McIntosh, 2010). This, coupled with online discussion from peers outside the group, enabled learning success both in and out of class.

Though frequently used in tertiary teaching, only two identified studies reported using a wiki to teach health professionals and both described collaborative projects. In one study, graduate nursing students completing a community health collaborative project were positive toward their use of a wiki and reported it increased their appreciation of group work (Ciesielka, 2008). Another study with medical students found the collaborative wiki environment was an effective method for introducing clinical skills and correlating anatomy with clinical diagnoses (Philip, Unruh, Lachman \& Pawlina, 2008). The medical students used clinical skills and reasoning to create a patient case using a wiki, similar to the student tasks in the current study. The current findings are consistent with these reports, as students reported the wiki facilitated their collaboration as a group. Observations indicated the wiki was useful for encouraging participation from quieter members of a group and those with English as a second language, who might be less likely to speak up during face to face group meetings. This provides supporting evidence that a wiki facilitates collaboration among students' study in the health disciplines.

\section{Student engagement and opinion}

Although there is evidence that wikis facilitate collaborative learning, participation rates in wiki based activities vary. Technology, arts and publishing students have been shown to be more likely to use wikis than students in health and social sciences (Ramanau \& Geng, 2009), and engagement appears linked to assessment requirements for wiki activities. Wiki participation was quite low in some studies (Cole, 2009; Cubric, 2007; Neumann \& Hood, 2009; Ramanau \& Geng, 2009) with students reporting they only contributed due to their assessment requirements (Cubric, 2007). 
Ebner et al. (2008) suggest that if a wiki is too complicated, or not linked to assessment, then students are not likely to participate. Likewise, a study by Cole (2009) with third year computer science students found that without a link to specific learning activities, the wiki had little impact on student engagement due to a lack of student interest and online contributions. In contrast, another study with undergraduate and postgraduate business students reported sufficient student engagement and participation when all course assessment occurred within the Wiki (Ruth \& Houghton, 2009). Differences in assessment requirements and incentives for participation are likely reasons for the variability in participation rates observed in different studies.

In the current study, wiki participation was high, likely because activities were linked with specific learning objectives and associated required assessment. There were large numbers of page contributions and views by students, suggesting the assessment criteria linked to each learning activity may have facilitated participation. However, despite satisfactory participation from the majority of students, there were still some students who did not engage with the wiki. The motivating factors for these individual students are unknown, as student survey data was anonymous. As assessment was a major motivating factor reported by students, potentially increasing the value of assessment associated with wiki participation may further improve engagement. Mentor and tutor contributions were also highly valued by students, and additional feedback from these groups may also increase student engagement (Cubric, 2007). Previous research suggests that a range of factors such as time spent using the wiki, sufficient student capability and educator attitudes towards the wiki can influence motivation for its use (Guo \& Stevens, 2011), and these factors were not evaluated in the current study. Nevertheless, student engagement with the wiki was viewed as satisfactory overall, and was greater than initially anticipated.

Student responses to wiki learning in the current study were both positive and negative, consistent with previous studies. Many previous studies report technical issues and organisational barriers (Neumann \& Hood, 2009; Peterson, 2009; Ramanau \& Geng, 2009; Ruth \& Houghton, 2009) and recommend allowing adequate time for introducing wiki technology (Cubric, 2007; Ramanau \& Geng, 2009). Students in the current study placed more value on their in class sessions rather than the wiki, and many struggled with technological aspects due to a lack of familiarity with wiki. For some students, using the wiki was time consuming and frustrating. Despite the difficulties, a considerable number of students reported their learning benefitted from the wiki. Previous studies also report learning benefits from wikis, including assistance with revision, consolidation, and as a resource for future reference (Matthew \& Felvegi, 2009; Peterson, 2009; Ramanau \& Geng, 2009).

\section{Effect of wiki on learning}

The learning environment and the objectives of a learning activity will influence whether a wiki is an effective medium for learning. Prior research indicates that wikis may be more effective for open ended discussion and reflection (Ramanau \& Geng, 2009) rather than as a tool to improve writing skills. Neumann and Hood (2009) found no difference between using a wiki or individual word processing software in student performance (i.e., grades) on a written assignment. However, the students who used the wiki had higher rates of engagement. This suggests that although student engagement may be enhanced using a wiki, assessment performance does not necessarily improve, especially if the learning task is not suited to the wiki environment. When using online activities such as a wiki for learning, tasks should be 
interactive and engaging (Crisp, 2002), designed around authentic learning and assessment activities that replicate real world experiences (Crisp, 2008). This will ensure that student learning needs are met through the design, instruction and methods of teaching.

In the current example, the opportunity for students to revise content through interaction with their mentor, and the need for students to respond to questions from peers outside their group, facilitated a stepped learning process. This is similar to clinical reasoning with a client, where a practitioner must accept or reject various clinical hypotheses based on information gained from client assessment. Thus the wiki provided a vehicle to practice clinical reasoning in an environment without time pressure or other stresses related to treating a patient.

\section{Recommendations for teachers}

The current study provides insight on strategies to enhance learning effectiveness and overcome difficulties when using a wiki in teaching. Activities need to be simple, valuable and relevant to learning outcomes and authentic (workplace) situations. Careful organisation of activities is recommended to enhance the learning benefits of using a wiki, and a structured and organised program design will assist with student understanding of the wiki learning objectives. Clear expectations for students with links to assessment will enhance engagement. Optional technical training for students and tutors may improve time efficiency with using a wiki and increase satisfaction, and specific guidelines for tutor feedback may help to ensure equity. Though setting up a wiki activity can be time consuming for course coordinators, wikis require minimal maintenance (Peterson, 2009), as students independently direct much of their learning through their interactions with each other. In the current example, educator time was saved by reducing the need for additional face to face teaching hours, which would be required for all student groups to discuss their patient cases in the required depth; much of this discussion took place on the wiki with an overview presented to the class.

Wikis compel students to make an effort to engage in learning, rather than being passive recipients. The high student engagement in the current study suggests that collaborative learning using a wiki is potentially more successful when combined with face to face activity and assessment, than if the wiki was used alone. Despite the negative responses of some students about the wiki's cumbersome nature, student collaboration and engagement were enhanced by using it. Students had to use their reasoning skills to accept or reject alternate opinions and evaluate information and decisions made by other students. These critical thinking skills are closely aligned with the interactions of health professionals in clinical practice, and assisted in developing students' reasoning skills in an authentic manner.

\section{Limitations}

Results are limited to one cohort of students in physiotherapy at a single university, which limits generalisability. Responses may be unique to health or physiotherapy students who are high achievers, and it is unknown whether the same results would be obtained in different student cohorts, universities or geographical areas. However, the student participants had no specific Internet or technology training, which suggests that a wiki can be used effectively for naive technology users. 


\section{Future research}

Future research should investigate whether a wiki is effective with other groups of health students or with other learning tasks, and whether skills learned using a wiki transfer to the real world setting. Evaluating the present wiki activity with other physiotherapy student cohorts or groups of health students would increase the generalisability of the results. Additionally, it is unknown whether other collaborative learning activities such as practical skills training could be enhanced using a wiki. Trentin (2009) has developed an assessment tool for evaluating the collaborative process in a wiki environment. This may be useful for investigating the benefits of a wiki for different learning activities. Transfer of learning to the work setting could be investigated by auditing student performance scores on work-integrated placements or surveying supervisors of students. These future studies will contribute to knowledge about whether the wiki is beneficial for learning in varying contexts.

\section{Conclusion}

Combining a wiki with in-class activities can facilitate collaboration among students to enhance their learning of the complex critical thinking skill of clinical reasoning. An emphasis on using authentic tasks on the wiki, linking to assessment and communicating to students the purpose of the learning activity may increase student perception of the value of using a wiki. Greater learning benefits may also result from using blended learning methods that accommodate different learning styles and abilities.

\section{Acknowledgments}

The author would like to acknowledge David Gibson for assistance with data collection and Emma Sheaves for assistance with early drafts of this manuscript.

\section{References}

Ajjawi, R. \& Higgs, J. (2008). Learning to communicate clinical reasoning. In J. Higgs, M. A. Jones, S. Loftus \& N. Christensen (Eds.), Clinical reasoning in the health professions (3rd ed., pp. 3-17). Philadelphia: Elsevier Butterworth Heinemann.

Anderson, L. W. \& Krathwohl, D. R. (Eds.) (2001). A taxonomy for learning, teaching, and assessing: A revision of Bloom's taxonomy of educational objectives. New York: Addison Wesley Longman.

Arnold, N. \& Ducate, L. (2006). Future foreign language teachers' social and cognitive collaboration in an online environment. Language Learning $\mathcal{E}$ Technology, 10(1), 42-66. http: / / llt.msu.edu/vol10num1/pdf/arnoldducate.pdf

Augar, N., Raitman, R. \& Zhou, W. (2006). Developing wikis to foster web-based learning communities: An iterative approach. International Journal of Web Based Communities, 2(3), 302317. http:/ / dx.doi.org/10.1504/IJWBC.2006.011761

Beaudoin, M. F. (2002). Learning or lurking? Tracking the "invisible" online student. The Internet and Higher Education, 5, 147-155. http: / / dx.doi.org/10.1016/S1096-7516(02)00086-6

Ben-Zvi, D. (2007). Using wiki to promote collaborative learning in statistics education. Technology Innovations in Statistics Education, 1(1), 1-18. http: / / escholarship.org/uc/item/6jv107c7 
Bold, M. (2006). Use of wikis in graduate course work. Journal of Interactive Learning Research, 17(1), 5-14. http: / / www.editlib.org/p/6033

Brack, C. \& Van Damme, M.-P. (2009). The wiki factor: How students learn to love group work. Readings in Technology and Education: Proceedings of ICICTE 2009.

Bradley, D., Noonan, P., Nugent, H. \& Scales, B. (2008). Review of Australian Higher Education Final Report. Canberra: Commonwealth of Australia. http:/ / www.deewr.gov.au/Higher Education/Review/Pages/ReviewofAustralianHigherEducationReport.aspx

Buffington, M. L. (2008). Creating and consuming Web 2.0 in art education. Computers in the Schools, 25(3-4), 303-313. http:/ / dx.doi.org/10.1080/07380560802365898

Burgess, J. (2008). Managing the new workforce: Generation Y (millennials). [viewed 7 May 2010, verified 18 Jun 2011] http:/ / www.redfusionmedia.com/arc_managing_generation_Y_millennials.htm

Carr, N. (2008). Wikis, knowledge building communities and authentic pedagogies in preservice teacher education. In Hello! Where are you in the landscape of educational technology? Proceedings ascilite Melbourne 2008. http: / / www.ascilite.org.au/conferences/melbourne08/ procs/ carr-n.pdf

Caverly, D. C. \& Ward, A. (2008). Techtalk: Wikis and collaborative knowledge construction. Journal of Developmental Education, 32(2), 36-37. http: / / www.eric.ed.gov:80 / ERICWebPortal/ contentdelivery/servlet/ERICServlet?accno=EJ868667

Chen, Y.-C. (2007). Wiki technology as a scaffolding tool in education. Proceedings ISM Workshops 2007 9th IEEE International Symposium on Multimedia - Workshops, 459-463. http: / / doi.ieeecomputersociety.org/10.1109/ ISM.Workshops.2007.83

Choy, S. O. \& Ng, K. C. (2007). Implementing wiki software for supplementing online learning. Australasian Journal of Educational Technology, 23(2), 209-226. http: / / www.ascilite.org.au/ajet/ajet23/choy.html

Ciesielka, D. (2008). Using a wiki to meet graduate nursing education competencies in collaboration and community health. Journal of Nursing Education, 47(10), 473-476. http: / / www.slackjournals.com/ article.aspx?rid=34249

Cole, M. (2009). Using wiki technology to support student engagement: Lessons from the trenches. Computers \& Education, 52(1), 141-146. http: / / www.pgce.soton.ac.uk/ict/NewPGCE/ PDFs09/Using\%20wiki\%20to\%20support $\% 2$ 0student $\%$ 20engagement $\% 20$ lessons $\% 20$ from $\% 20$ the $\%$ 20trenches.pdf

Crisp, G. T. (2002). Using Java applets to help make online assessment interactive. In Winds of change in the sea of learning. Proceedings ASCILITE Auckland 2002.

http:/ / www.ascilite.org.au/conferences/ auckland02/ proceedings / papers / 096.pdf

Crisp, G. T. (2008). Raising the profile of diagnostic, formative and summative e-assessments. Providing e-assessment design principles and disciplinary examples for higher education academic staff. Strawberry Hills, NSW: Australian Learning \& Teaching Council Ltd. http: / / www.altc.edu.au / resource-raising-profile-eassessments-crisp-adelaide-2008

Cubric, M. (2007). Wiki-based process framework for blended learning. In WikiSym '07: Proceedings of the 2007 International Symposium on Wikis, pp. 11-24. http:/ / doi.acm.org/10.1145/1296951.1296953 
Ebner, M., Kickmeier-Rust, M. \& Holzinger, A. (2008). Utilizing wiki-systems in higher education classes: A chance for universal access? Universal Access in the Information Society, 7(4), 199-207. http: / / dx.doi.org/10.1007/s10209-008-0115-2

Elgort, I., Smith, A. G. \& Toland, J. (2008). Is wiki an effective platform for group course work? Australasian Journal of Educational Technology, 24(2), 195-210. http: / / www.ascilite.org.au/ajet/ajet24/elgort.html

Elliot, B. (2007). Modernising assessment: the use of Web 2.0 for formative and summative assessment. In F. Khandia (Ed.), 11th CAA International Computer Assisted Conference, Loughborough, pp. 179-188. http:/ / hdl.handle.net/2134/4543

Giannoukos, I., Nikolopoulos, V., Lykourentzou, I., Ioumos, V., Mpardis, G. \& Kayafas, E. (2008). Collaborative e-learning environments enhanced by wiki technologies. In PETRA'08. Proceedings of the 1st international conference on PErvasive Technologies Related to Assistive Environments, Athens, Greece. http:/ / dx.doi.org/10.1145/1389586.1389657

Guo, Z. \& Stevens, K. J. (2011). Factors influencing perceived usefulness of wikis for group collaborative learning by first year students. Australasian Journal of Educational Technology, 27(2), 221-242. http:/ / www.ascilite.org.au/ajet/ajet27/guo.html

Health Professions Council of Australia (2005). The allied health professional workforce in Australia: Challenges and opportunities. Submission to the Productivity Commission Health Workforce Study. Melbourne. http:/ / www.ahpa.com.au/pdfs/submission_08.05.pdf

Heinze, A. \& Procter, C. (2004). Reflections on the use of blended learning. In Education in a Changing Environment. Conference proceedings, 13-14 September, University of Salford. http: / / usir.salford.ac.uk/1658/

Higgs, J. (2004). Educational theory and principles related to learning clinical reasoning. In M. A. Jones \& D. A. Rivett (Eds.), Clinical reasoning for manual therapists. Edinburgh: ButterworthHeinemann.

Higgs, J. \& Jones, M. A. (2008). Clinical decision making and multiple problem spaces. In J. Higgs, M. A. Jones, S. Loftus \& N. Christensen (Eds.), Clinical reasoning in the health professions (3rd ed., pp. 3-17). Philadelphia: Elsevier Butterworth Heinemann.

Hunt, A. \& Higgs, J. (1999). Learning generic skills. In J. Higgs \& H. Edwards (Eds.), Educating beginning practitioners: Challenges for health professional education. Oxford: ButterworthHeinemann.

Jones, M. A. \& Rivett, D. A. (Eds) (2004). Clinical reasoning for manual therapists. Edinburgh: Butterworth-Heinemann.

Judd, T., Kennedy, G. \& Cropper, S. (2010). Using wikis for collaborative learning: Assessing collaboration through contribution. Australasian Journal of Educational Technology, 26(3), 341354. http:/ / www.ascilite.org.au/ajet/ajet26/judd.html

Kaufman, D. R., Yoskowitz, N. A. \& Patel, V. L. (2008). Clinical reasoning and biomedical knowledge: Implications for teaching. In J. Higgs, M. A. Jones, S. Loftus \& N. Christensen (Eds.), Clinical reasoning in the health professions (3rd ed., pp. 3-17). Philadelphia: Elsevier Butterworth Heinemann.

Kirschner, P. A. (2004). Design, development, and implementation of electronic learning environments for collaborative learning. Educational Technology Research and Development, 52(3), 39-46. http:/ / dx.doi.org/10.1007/BF02504674 
Leuf, B. \& Cunningham, W. (2001). The wiki way: Quick collaboration on the web. Boston, MA: Addison-Wesley Longman Publishing Co.

Matthew, K. I. \& Felvegi, E. (2009). Learning course content by creating a wiki. TechTrends, 53(3), 67-73.

McIntosh, C. \& Weaver, D. (2008). Fostering collaboration amongst off-campus students. In Hello! Where are you in the landscape of educational technology? Proceedings ascilite Melbourne 2008. http: / / www.ascilite.org.au/conferences/melbourne08/procs/mcintosh.pdf

McPherson, K. (2006). Wikis and literacy development. Teacher Librarian, 34(1), 4.

Michalski, K. (2008). Learning styles and blended learning: Challenges and opportunities in distance education environment. In Proceedings of World Conference on E-learning in Corporate, Government, Healthcare and Higher Education 2008, Chesapeake, VA: AACE. http: / / www.editlib.org/p/28980

Neumann, D. L. \& Hood, M. (2009). The effects of using a wiki on student engagement and learning of report writing skills in a university statistics course. Australasian Journal of Educational Technology, 25(3), 382-398.

http:/ / www.ascilite.org.au/ajet/ajet25/neumann.html

Nicol, D., Littlejohn, A. \& Grierson, H. (2005). The importance of structuring information and resources within shared workspaces during collaborative design learning. Open Learning, 20(1), 31-49. http:/ / dx.doi.org/10.1080/0268051042000322087

Oblinger, D. (2005). Learners, learning and technology: The Educause learning initiative. EDUCAUSE Review, 40(5), 67-75. http: / / net.educause.edu/ir/library/pdf/erm0554.pdf

Pasole, S. \& Awalt, C. (2008). Team-based learning in asynchronous online settings. New Directions for Teaching and Learning, 116, 87-95. http: / / dx.doi.org/10.1002/ tl.336

Peterson, E. (2009). Using a wiki to enhance cooperative learning in a real analysis course. Primus, 19(1), 18-28. http:/ / dx.doi.org/10.1080/10511970802475132

Philip, C. T., Unruh, K. P., Lachman, N. \& Pawlina, W. (2008). An explorative learning approach to teaching clinical anatomy using student generated content. Anatomical Sciences Education, 1(3), 106-110. http: / / dx.doi.org/10.1002/ ase.26

Proctor, C. (2003). Blended learning in practice. In Inaugural Education in a Changing Environment Conference. Salford, University of Salford.

Ramanau, R. \& Geng, F. (2009). Researching the use of wikis to facilitate group work. Procedia Social and Behavioral Sciences, 1(1), 2620-2626. http: / / dx.doi.org/doi:10.1016/j.sbspro.2009.01.463

Riehle, D. \& Bruckman, A. (Eds) (2009). Proceedings of the 5th International Symposium on Wikis and Open Collaboration (WikiSym '09). [viewed 7 May 2010, verified 18 Jun 2011] http:/ / www.wikisym.org/ws2009/ Proceedings

Ruth, A. \& Houghton, L. (2009). The wiki way of learning. Australasian Journal of Educational Technology, 25(2), 135-152. http:/ / www.ascilite.org.au/ajet/ ajet25/ruth.html

Sheehy, G. (2008). The wiki as knowledge repository: Using a wiki in a community of practice to strengthen K-12 education. TechTrends, 52(6), 55-60. http:/ / dx.doi.org/10.1007/s11528-0080219-9 
Stahmer, T. (2006). Think outside the blog. Technology and Learning, 26(6), 1-2. http: / / www.techlearning.com/article/5158

Staley, D. J. (2009). Managing the platform: Higher education and the logic of wikinomics. EDUCAUSE Review, 44(1), 36-47.

http: / / www.educause.edu /EDUCAUSE+Review / EDUCAUSEReviewMagazineVolume44 / ManagingthePlatformHigherEduca/163579

Tan, S. M., Ladyshewsky, R. K. \& Gardner, P. (2010). Using blogging to promote clinical reasoning and metacognition in undergraduate physiotherapy fieldwork programs. Australasian Journal of Educational Technology, 26(3), 355-368. http: / / www.ascilite.org.au/ajet/ajet26/tan.html

Trentin, G. (2009). Using a wiki to evaluate individual contribution to a collaborative learning project. Journal of Computer Assisted Learning, 25(1), 43-55. http: / / dx.doi.org/10.1111/j.13652729.2008.00276.x

Turpin, M. \& Higgs, J. (2010). Clinical reasoning and evidence-based practice. In T. Hoffman, S. Bennett \& C. Del Mar (Eds.), Evidence-based practice across the health professions (pp. 300-317). Sydney: Churchill Livingstone.

Weaver, D., Viper, S., Latter, J. \& McIntosh, P. C. (2010). Off campus students' experiences collaborating online, using wikis. Australasian Journal of Educational Technology, 26(6), 847-860. http: / / www.ascilite.org.au/ajet/ajet26/weaver.html

Wheeler, S. \& Wheeler, D. (2009). Using wikis to promote quality learning in teacher training. Learning, Media and Technology, 34(1), 1-10. http: / / dx.doi.org/10.1080/17439880902759851

Wheeler, S., Yeomans, P. \& Wheeler, D. (2008). The good, the bad and the wiki: Evaluating student-generated content for collaborative learning. British Journal of Educational Technology, 39(6), 987-995. http: / / www.pgce.soton.ac.uk/ict/NewPGCE/PDFs/The\%20good\%20 the $\% 20$ bad $\% 20$ and $\% 20$ the $\% 20$ wiki.pdf

Zorko, V. (2009). Factors affecting the way students collaborate in a wiki for English language learning. Australasian Journal of Educational Technology, 25(5), 645-665.

http:/ / www.ascilite.org.au/ajet/ajet25/zorko.html

Author: Dr Suzanne Snodgrass, Discipline of Physiotherapy

School of Health Sciences, Hunter Building

The University of Newcastle, Callaghan, NSW 2308

Email: Suzanne.Snodgrass@newcastle.edu.au

Please cite as: Snodgrass, S. (2011). Wiki activities in blended learning for health professional students: Enhancing critical thinking and clinical reasoning skills. Australasian Journal of Educational Technology, 27(4), 563-580.

http: / / www.ascilite.org.au/ajet/ajet27 / snodgrass.html 